\title{
Pre-operative Evaluation
}

National Cancer Institute

\section{Source}

National Cancer Institute. Pre-operative Evaluation. NCI Thesaurus. Code C139982.

An examination of an individual to determine their health status prior to a surgical

procedure and their suitability for the procedure. 